\title{
Case Report: Lesson Learned from Rehabilitation Medicine Point of View for an Elderly with Normal Pressure Hydrocephalus
}

\author{
Irma Ruslina Defi ${ }^{1 *} \mathbb{D}$, Andre Andre ${ }^{1}$, Sunaryo Barki Sastradimadja ${ }^{1}$, Ahmad Faried ${ }^{2} \mathbb{D}$ \\ ${ }^{1}$ Department of Physical Medicine and Rehabilitation, Faculty of Medicine, Padjadjaran University, Hasan Sadikin Academic \\ Hospital, Bandung, Indonesia; ${ }^{2}$ Department of Neurosurgery, Faculty of Medicine, Padjadjaran University, Hasan Sadikin \\ Academic Hospital, Bandung, Indonesia
}

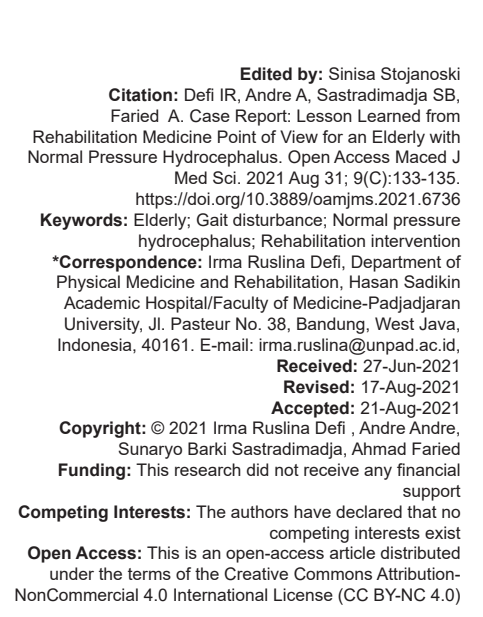

Abstract

BACKGROUND: Normal pressure hydrocephalus (NPH) is characterized by an abnormal buildup of cerebrospinal fluid in the ventricles or cavities of the brain. The objective of the case report was to define the importance of physical medicine and rehabilitation intervention as an approach for an elderly patient with $\mathrm{NPH}$.

CASE REPORT: A 75-year-old woman presented with a balance and gait disturbance after injury from a motor vehicle accident. The patient experience Hakim's triad (gait disturbance, urinary frequency, and mild cognitive impairment), and her computed tomography scan of the head revealed ventriculomegaly, multiple lacunar infarctions on the paraventricle, and cerebral atrophy, which could indicate NPH. Balance and gait training, cardiopulmonary training, and environment modification were interventions from physical medicine and rehabilitation provided to this patient.

CONCLUSION: An elderly patient with NPH should receive physical medicine and rehabilitation intervention to prevent falls, improve functional ability, and improve quality of life.

\section{Introduction}

Normal pressure hydrocephalus (NPH) is a brain disorder in which excess cerebrospinal fluid accumulates in the ventricles of the brain, causing problems with thinking and reasoning, difficulty walking, and bladder control (Hakim's triad) [1]. The efficacy of rehabilitation and its specific therapeutic interventions for NPH has not been investigated empirically and systematically.

The objective of this case report is to provide insight into the advantage of physical medicine and rehabilitation intervention to improve functional outcomes for an elderly patient with $\mathrm{NPH}$.

\section{Case Report}

A 75-year-old woman, a homemaker, presented with unsteadiness when walking 4 years ago after an injury from a motor vehicle accident. She had already given consent to participate in this case report. The patient felt unsteadiness while standing with her eye closed. The patient also felt that she walked slightly to the right when trying to walk straight forward. One year ago, the unsteadiness became worse, and difficult to get up from a chair and be supported by her husband while walking outside the house. However, she still can do Activities of Daily Living (ADL) and Instrumental ADL independently. She regularly consumes piracetam $800 \mathrm{mg}$ once a day, mecobalamin $500 \mathrm{mg}$ twice a day, and bone supplements once a day. She has no financial burden to get medical access. She had a kyphotic pelvic with posterior tilting according to the schematic representation of kyphotic (Figure 1) [2]. Her neurological examination revealed that she had an impairment of heel to shin coordination test, particularly on the right side.

NPH grading scale was used to measure the functional assessment. The cognitive impairment score was 1 (amnesia or inattention but no objective memory and attentional impairment). The gait disturbance score was 2 (unstable but independent gait), and the 
urinary disturbance score was 1 (pollakiuria or urinary urgency) [3].

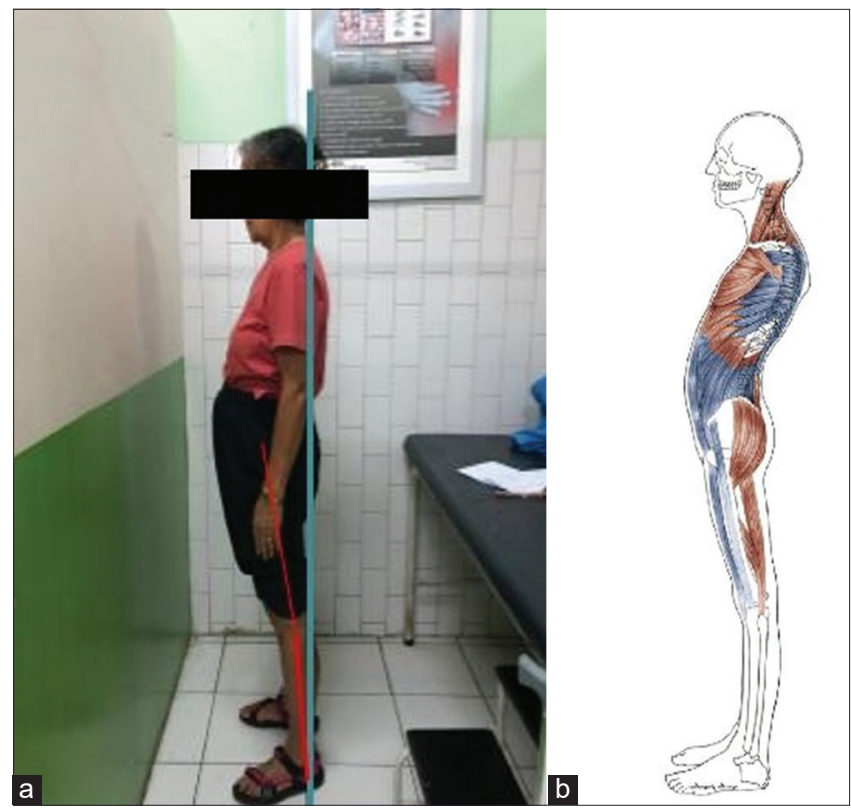

Figure 1: Image of kyphotic pelvic. (a) Sway Back Posture lateral view of the patient in this case report that leads to falling. (b) Schematic representation of the shortened (red) and lengthened (blue) skeletal muscles [2]

Quality of life (QoL) for NPH using 15D instrument HRQoL (15-D) [4] score was 23. We found a slow, short-stepped gait, wide base, and difficulty turning around on gait analysis. The scale for the assessment and rating of ataxia was $9 / 44$ with the gait scale: $3 / 8$, stance $3 / 6$, finger chase $2 / 4-1 / 4$, and hellshin slide 2/4-1/4. Romberg test stabilometry in Eyes open (EO) path length was $129.2 \mathrm{~cm}$, Eyes closed (EC) path length was $302.3 \mathrm{~cm}$, EO Area was $12.5 \mathrm{~cm}^{2}$, EC Area was $25.7 \mathrm{~cm}^{2}$, EO/EC Length was $2.34 \mathrm{~cm}^{2}$, EO/EC Area was $2.05 \mathrm{~cm}^{2}$. Ventriculomegaly, multiple lacunar infarctions on the paraventricle and cerebral atrophy were observed in the computed tomography (CT) scan, supporting the diagnosis of NPH (Figure 2).

The goals of our physical medicine and rehabilitation intervention were the patient and family understanding of her condition and functional prognosis, controlling fear of fall, improving static and dynamic balance, increasing safe walking $(>0.8 \mathrm{~m} / \mathrm{s})$, walking outdoor independently with an assistive device, an increase of the cardiopulmonary endurance (Metabolic Equivalents/METS target: 4-5), improving QoL, preventing progression of frailty condition, and maintaining the role as a homemaker. To support these goals, we gave physical medicine and rehabilitation intervention such as (1) balance exercise program for 12 weeks of training, consist of static and dynamic balance; (2) gait training on a treadmill and walking with a cane; (3) cardiopulmonary endurance training with leg ergo cycle; (4) resistance training for hip stabilization with sit to stand and resistance band; and (5) family meeting for house modification and caregiver for supervision to prevent falls.

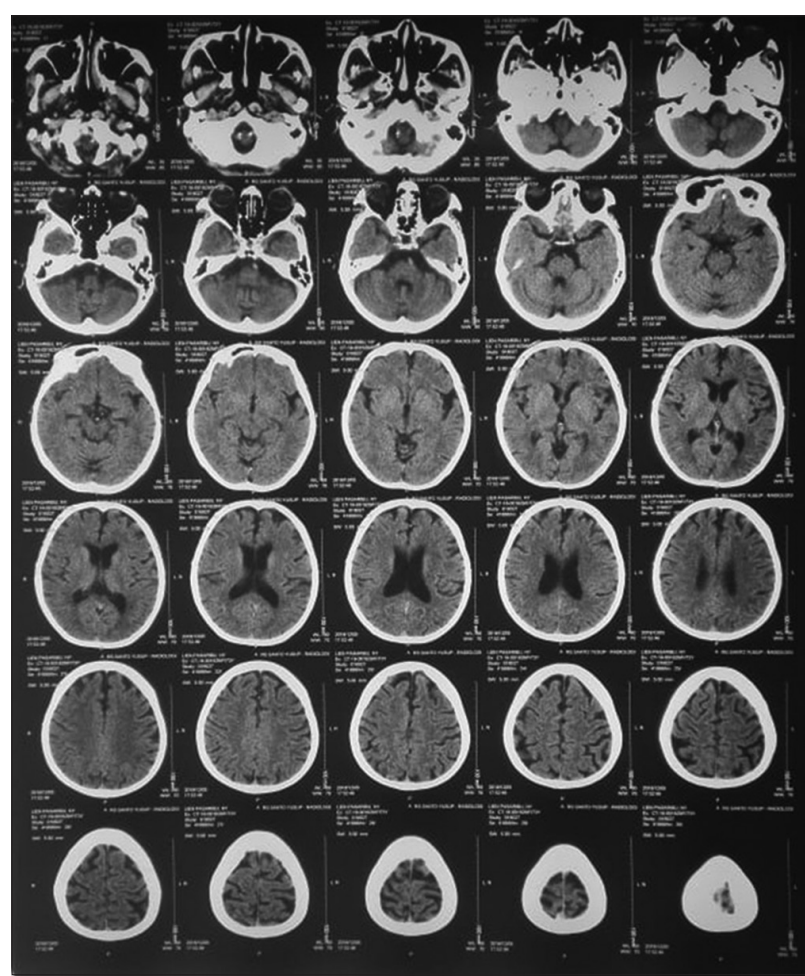

Figure 2: Head computed tomography (CT) scan of the patient. Ventriculomegaly, multiple lacunar infarctions on paraventricle, and cerebral atrophy were observed in CT scan, supporting the diagnosis of normal-pressure hydrocephalus

\section{Discussion}

The patient had a slower walking speed $(0.52 \mathrm{~m} / \mathrm{s})$ which mostly required help because she walked slower than $0.6 \mathrm{~m} / \mathrm{s}$. In addition, there was a slight deficit in proprioception and coordination, especially on the right side and swayback posture (Figure 1). She was also positive for the Romberg test, suggesting that she relied on postural control on visual aid. The remaining possible causes of balance and gait disorder in this patient were sensory input abnormalities, decreased signal processing, fear of falling, and decreased muscle strength and coordination because of aging, lacunar infarct, traumatic brain injury, and inactivity.

NPH should always be considered as the differential diagnosis of patients who present with its characteristic manifestations. NPH should be treated as soon as possible if the diagnosis is confirmed [3], [5].

During upright standing, our patient has a decrease proprioceptive threshold for the perception of body sway, compared with vestibular and visual systems, proprioceptive inputs have an important role in postural control. Changes in the proprioceptive signal are likely to raise the risk of falling and make it more difficult to decrease fall-related trauma [6].

The most effective approach for fall prevention is a multifactorial evaluation accompanied by targeted 
interventions for identified contributing factors, which could decrease falls by $30-40$ percent. The treadmill was used as one of the habituation interventions for this patient to improve the walking pattern (Figure 3a).
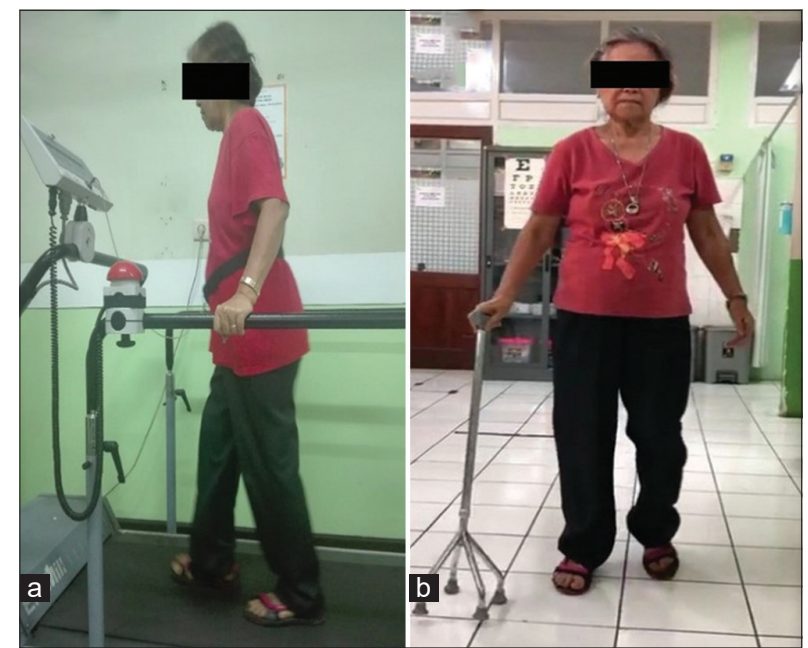

Figure 3: Targeted intervention. (a) Our patient exercises with the treadmill and (b) walks with the quadruped cane

To effectively improve mobility and decrease disability, it is important to choose the right assistive device and education from a medical professional. We prescribed the pivot standard cane with a quadruped tip as an assistive device for this patient (Figure $3 \mathrm{~b}$ ). It can stands freely on its own, but light and the pivot make the gait pattern less awkward [7].

Table 1: Functional improvement after rehabilitation program in our patient

\begin{tabular}{lll}
\hline Functional assessment & Day 1 & Day 28 \\
\hline Timed up and go test & $20 \mathrm{~s}$ & $15 \mathrm{~s}$ \\
30-s sit to stand without support & 7 times & 11 times \\
6-min walking test distance & $199 \mathrm{~m}$ & $240 \mathrm{~m}$ \\
VO2max predicted & $10 \mathrm{ml} / \mathrm{kg} / \mathrm{min}$ & $11.2 \mathrm{ml} / \mathrm{kg} / \mathrm{min}$ \\
Metabolic equivalents (METS) & 3.7 & 4.1 \\
Walking speed without cane & $0.52 \mathrm{~m} / \mathrm{s}$ & $0.67 \mathrm{~m} / \mathrm{s}$ \\
Walking speed with cane & $0.6 \mathrm{~m} / \mathrm{s}$ & $0.7 \mathrm{~m} / \mathrm{s}$ \\
Hand grip strength & $18.7 \mathrm{~kg}$ & $28 \mathrm{~kg}$ \\
Left & $10 \mathrm{~kg}$ & $14 \mathrm{~kg}$ \\
Right & $8.7 \mathrm{~kg}$ & $14 \mathrm{~kg}$ \\
Peak cough flow & $260 \mathrm{l} / \mathrm{s}$ & $310 \mathrm{l} / \mathrm{s}$ \\
\hline
\end{tabular}

This patient has been prescribed an exercise program that includes aerobic, resistance, flexibility, and balance exercise to improve her physical performance. During physical medicine and rehabilitation intervention, no adverse effects or unanticipated events happened to this patient. At the end of all physical medicine and rehabilitation interventions, our patient can achieve the goal and improve functional status. The patient feels satisfied with her achievement to maintain her role as a homemaker (Table 1). A serial case is needed to show a long-term evaluation.

\section{Conclusion}

This case report shows the importance of considering physical medicine and rehabilitation intervention for the elderly with NPH to prevent falls, improve functional ability, and QoL.

\section{References}

1. Hakim S, Adams RD. The special clinical problem of symptomatic hydrocephalus with normal cerebrospinal fluid pressure. Observations on cerebrospinal fluid hydrodynamics. J Neurol Sci. 1965;2(4):307-27. https://doi. org/10.1016/0022-510x(65)90016-x

\section{PMid:5889177}

2. Czaprowski D, Stoliński L, Tyrakowski M, Kozinoga M Kotwicki T. Non-structural misalignments of body posture in the sagittal plane. Scoliosis Spinal Disord. 2018;13:10. https://doi. org/10.1186/s13013-018-0151-5

PMid:29516039

3. Kiefer M, Unterberg A. The differential diagnosis and treatment of normal-pressure hydrocephalus. Dtsch Arztebl Int. 2012;109(1-2):15-26.

PMid:22282714

4. Junkkari A, Sintonen $H$, Nerg O, Koivisto AM, Roine RP, Viinamäki $\mathrm{H}$, et al. Health-related quality of life in patients with idiopathic normal pressure hydrocephalus. Eur J Neurol. 2015;22(10):1391-9. https://doi.org/10.1111/ene.12755 PMid:26104064

5. Souza RK, Rocha SF, Martins RT, Kowacs PA, Ramina R. Gait in normal pressure hydrocephalus: Characteristics and effects of the CSF tap test. Arq Neuropsiquiatr. 2018;76:324-31. https:// doi.org/10.1590/0004-282×20180037

PMid:29898079

6. Henry M, Baudry S. Age-related changes in leg proprioception: Implications for postural control. J Neurophysiol. 2019;122(2):525-38. https://doi.org/10.1152/jn.00067.2019 PMid:31166819

7. Bradley SM, Hernandez CR. Geriatric assistive devices. Am Fam Physician. 2011;84(4):405-11 